\title{
A Practical Probabilistic Design Procedure for LV Residential Distribution Systems
}

\author{
Ron Herman, Senior Member, IEEE, and C. Trevor Gaunt
}

\begin{abstract}
Two basic types of low voltage (LV) distribution exist in practice. The systems based on the European approach have long LV feeders whose sizing requires more careful design consideration than systems based on North American practice with shorter LV feeders. The most important criterion in conductor sizing is the correct estimation of the design loads. This paper describes the development and application of a probabilistic design method based on the Beta probability density function (pdf). The paper investigates an approximate approach for estimating load parameters in countries where a large load database is not available. This approach estimates the Beta parameters from the group after-diversity-maximum-demand (ADMD) for the customers.
\end{abstract}

Index Terms-Load modeling, low-voltage (LV) distribution, probabilistic methods.

\section{INTRODUCTION}

$\mathbf{T}$ HIS PAPER presents a summary of the procedure derived for the probabilistic design of LV distribution networks in a developing country such as South Africa. It concludes with a method for applying the procedure in other countries that might not have detailed load data.

According to Carr and McCall [1], there are broadly two main types of low voltage (LV) electrical distribution system practice; North American and European.

The European practice, as found in South Africa and many developing countries, is characterized by:

- use of single-phase, bi-phase, and three-phase MV/LV transformers-typically $16 \mathrm{kVA}, 32 \mathrm{kVA}$, and $25 \mathrm{kVA}$ to $500 \mathrm{kVA}$, with up to 300 homes per transformer;

- low load density;

- several long LV feeders per transformer;

- $50 \mathrm{~Hz}$ supply.

In the bi-phase system, the neutral is connected to the centre tap of the secondary winding of a single-phase transformer.

Network designs within the different frameworks may require different approaches but there are some common basic principles. Uncertainty associated with the customer loads due to their stochastic behavior is common to all the network designs. Traditional design procedures are deterministic and use average values for the uncertain loads. This representative load value is often referred to as the after diversity maximum demand (ADMD) and is based on the mean demand at system peak for

Manuscript received June 5, 2007; revised August 7, 2007. First published April 3, 2008; current version published September 24, 2008. Paper no. TPWRD-00317-2007.

The authors are with the University of Cape Town, Rondebosch, Western Cape 7701, South Africa (e-mail: ronald.herman@uct.ac.za; CT.Gaunt@uct.ac. za).

Color versions of one or more of the figures in this paper are available online at http://ieeexplore.ieee.org.

Digital Object Identifier 10.1109/TPWRD.2008.919041 a large number (typically about 1000) of customers belonging to a particular customer class. When considering the collective loading of a smaller group of customers, the loss of diversity is usually accounted for by applying a correction factor (diversity factor or the inverse, coincidence factor). Concern at the discrepancy of design calculations led to a comparative study of various deterministic design procedures in South Africa, revealing a large variation in results. The probabilistic design procedure described in this paper was then developed.

\section{Elements of AN LV Network Design Procedure}

In general, the design procedure of a LV network for residential consumers consists of a number of elements, the detail and scope of which depend on the preceding planning process. Most design procedures include the following components.

\section{A. The Type of Loads and Where They are to be Supplied}

To determine these components require the following considerations:

- the identification and quantification of the living standards measurement (LSM) of the target customer class;

- geographical parameters such as density and the proposed layout of the residential area with respect to roads etc.

\section{B. Estimation of the Target Load Magnitudes}

Customer loads may be estimated from a variety of related demographic parameters. Typical among these are:

- annual income per household;

- dwelling floor area;

- expected number of occupants.

In most countries the load per customer, for a given class, is expressed as the ADMD in kilovolt amperes. In all cases, a load model needs to be developed from statistical measurement.

An extensive load research program was commenced in South Africa in 1988 when microprocessor based data loggers were developed to synchronously measure customer loads [2]. The program has collected load data at a large number of sites throughout the country to date. Analysis of the load research data in South Africa extends this information to the representation of the skewness of the dispersion by using the Beta probability distribution. This description might not be familiar in other countries but a method is developed in Section VII of this paper that makes the approach generally applicable. Other countries may not have such extensive data but will have models by which the mean demand at system peak may be estimated.

\section{Specification of Design Parameters}

Design parameters are related to the customer load types and the available technology options. Load parameters should quan- 
tify the statistical characteristics of the stochastic behavior of the customers in a format that can be manipulated in the design calculations. This usually requires load parameters that express the mean value and as a measure of its dispersion for the given group of customers connected to the same point in the network.

Other design parameters will include the impedances of the available conductor material at the expected operating temperature. Thermal loading limits must be specified for the equipment as well as the allowable voltage constraints at the customer's terminals.

\section{Appropriate Calculation Algorithm}

The design procedure requires calculation algorithms that adequately account for the statistical properties of the design loads and the topology of the distribution technology. The design procedure described in this paper incorporates a probabilistic approach that uses the Beta probability distribution of loads. This method was developed and tested over some years and is now accepted as the only valid design algorithm in South Africa where it is published in the Standards document, NRS-034 [3]. The development of the algorithms is briefly described in Section IV. At a national conference the method was assigned the Herman-Beta method but in this paper will be referred to as the Beta-parameter method. Due to the method's generally unfamiliar approach, it was necessary to publish a set of benchmark results for calibration and comparison, described in Section VI

\section{E. General Applicability of Calculation Procedures}

When design methods are adopted into general practice they need to be amenable to incorporation in commercial computer packages. The step-wise calculation procedure of the Beta parameter method has been incorporated into such software packages developed in South Africa and Europe. Some programs include financial optimization as well as compliance with voltage drop limits.

\section{LOAD DATA COLlECTION AND MODELING}

This section describes the residential load data collection and modeling process developed for the South African electricity supply industry.

\section{A. Electrical Parameters of a Load}

In an electrical sense, loads may be represented as resistance, current or power. The form in which the load is modelled has implications for both the gathering of data and the analysis of the network. The loads of domestic consumers may be divided into two broad categories, based on the way in which they consume energy.

The first group of loads are voltage and time dependent. Typical examples are incandescent lights and room or space heaters. The resistance at operating temperature is constant and the power taken is voltage dependent. The appliances are used for periods independent of the voltage or the energy consumed. If the voltage decreases, the power and current decrease proportionally. Therefore, these loads may be represented as constant resistance loads.

The reduction in load with falling terminal voltage is used by supply authorities to reduce demand when generating capacity is constrained. The reverse effect is also evident when replacing an overloaded distribution transformer; improved voltage conditions produce an increase in the load supplied from the up-rated substation.

The second category of loads is voltage independent. For example, the thermostat of a hot water cylinder or an automatic kettle switches off the appliance when the water reaches the desired temperature. The amount of energy delivered to the water is independent of the voltage; if the voltage falls the water is merely heated for a longer period. While the appliance is switched on it behaves as a constant resistance load, but its duration of connection to the system depends on the power delivered. As the demand of a consumer is integrated over a specified period, the behavior of several such loads in the long term is similar to that of a constant power load, as usually modelled in high-voltage systems.

The representation of loads as current sinks provides an acceptable and convenient model for the following reasons.

- It is the best representation of the mixed loads typical for appliances of residential customers.

- The magnitude of the current-modelled load is independent of the voltage drop along a feeder or the distance from the source.

- The measurement of loads as currents can be carried out accurately and inexpensively.

- The representation of loads as power requires an iterative volt-drop calculation method.

- The current model is consistent with the observed behavior of real loads. The load reduces with reduced voltage, but to a lesser extent than would be expected of a pure resistance load.

- In traditional methods of volt-drop calculations in LV feeders, loads specified as powers are usually converted to equivalent load current at rated voltage.

The averaging or integrating period used to measure loads will affect slightly the validity of the current representation of loads.

It is usually assumed in the calculation of voltage drop that the load is at unity power factor. The great majority of consumers' high load appliances are resistive, including water heaters, stoves and space heaters. Measurements taken by supply authorities confirm that the assumption of unity power factor is valid at the time of system peak loading, which represents the constraining condition for the system.

\section{B. South African Data Logger}

Data collection is performed by a data logger that meets the needs of the load survey. Essentially, the main features are:

- storage of samples that have been averaged over a preset averaging interval derived from half-second filtered measurements;

- sampling interval is $5 \mathrm{~min}$;

- accurate on-board real-time clock to ensure synchronous measurement with other loggers;

- all the data is logger- and time-tagged, and in a format that is compatible with spreadsheet software;

- loggers are weather and insect resistant;

- they are inexpensive so that a large number of samples may be collected. 


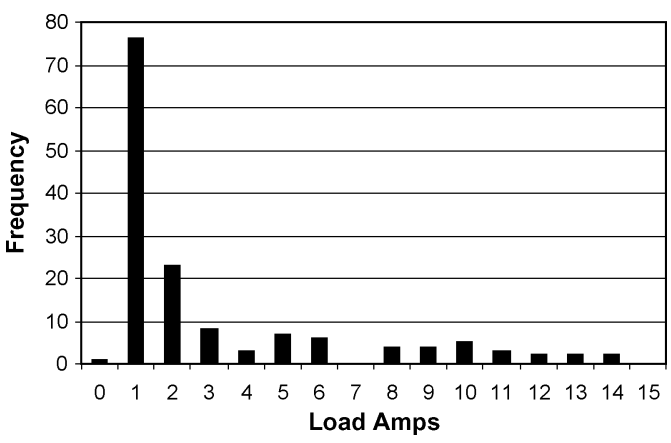

Fig. 1. Typical histogram of the load current distribution for a low-income group at the time of the group's maximum demand.

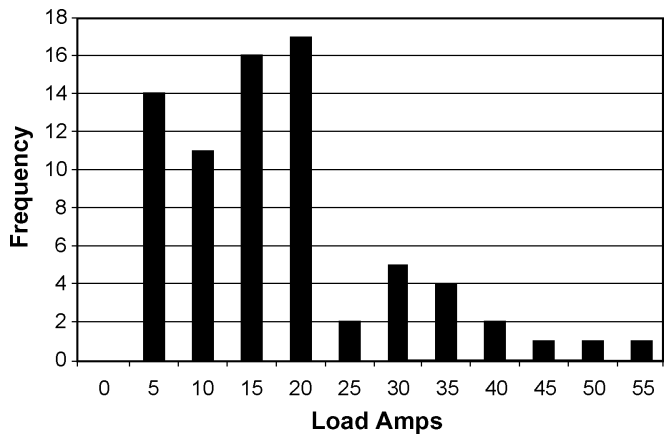

Fig. 2. Typical histogram of the load current distribution for a middle income group at the time of the group's maximum demand.

A central database has been established to receive all the collected data. The database is intended to be a national resource in South Africa. Provision has been made to make data available to researchers. The current data base has some $30 \mathrm{~GB}$ of data. Analysis software has been developed for interrogating the data to ensure data quality and also for extracting pertinent design parameters.

\section{Typical Load Current Histograms}

By collecting a statistically sufficient number of load current samples (the sample sizes for Figs. 1-3 were greater than 70), it is possible to identify the common interval in which the maximum demand for the group occurs. It is also possible then to determine the distribution of currents at that interval. These are conveniently represented as histograms as typified in Figs. 1 and 2.

It is quite obvious from this example that the probability distribution describing load currents is not symmetrical and can be very skew.

The distribution of currents in Fig. 2 shows less skewness, more conformity within the group. It is clear from the examples typified that the probability distribution function chosen to represent the load currents of residential customers needs to represent mean, dispersion, and skewness.

\section{Statistical Modeling-Beta Probability Density Function Fit}

Extensive work was done to identify the most appropriate pdf to represent the load current data [4]. For a variety of reasons the Beta pdf was found to be the most suitable. Fig. 3 shows a Beta pdf fit.

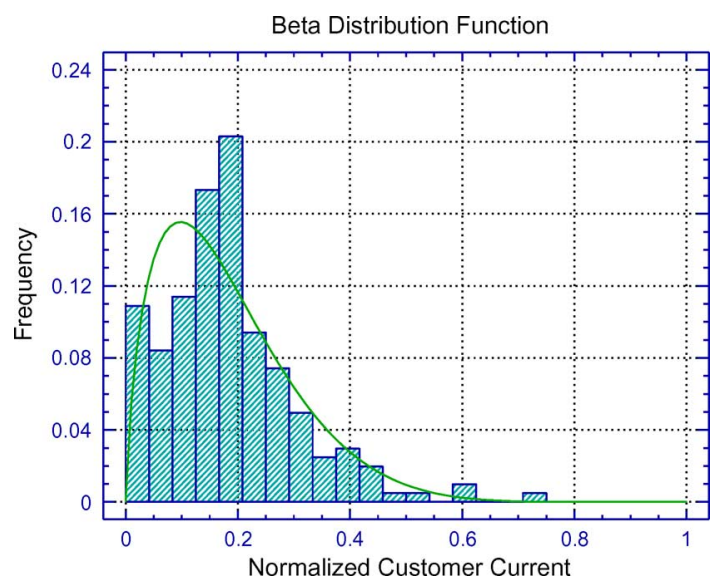

Fig. 3. Beta pdf fitted to load current data.

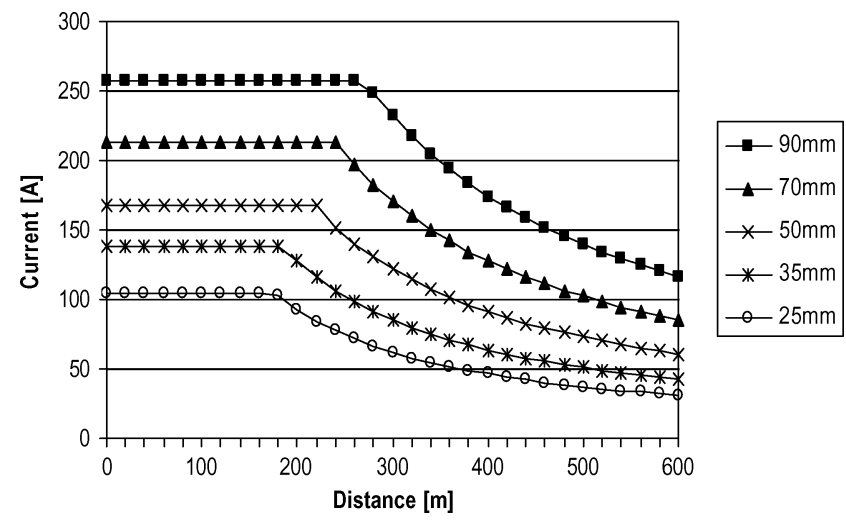

Fig. 4. Feeder current and voltage constraints versus length.

The important reasons for the use of the Beta pdf include:

- it is constrained to a finite base in the same way that the load currents are confined between 0 and the circuit breaker limit, C;

- it can be negatively and positively skewed;

- its parameters $\alpha$ and $\beta$ can easily be found from data;

- it performs well in "Goodness of Fit" tests on real load data using both Kolmogoroff-Smirnoff and Chi-square tests;

- it is conducive to convenient statistical analysis since the moments are gamma functions;

- it can be incorporated into voltage drop calculations, eliminating the need to use diversity correction curves.

\section{Development of a Probabilistic Voltage DROP CALCUlation METHOD}

When designing the LV networks in the European style of distribution (or when the laterals have appreciable length with several connected consumers) it is found that voltage drop is the major constraint in sizing conductors. This is illustrated by the graph in Fig. 4 for various sizes of single conductor, each carrying its allowable maximum continuous current, constrained to a maximum voltage drop of $10 \%$.

In developing the probabilistic design method, we make the following assumptions.

- The maximum voltage drop occurs at the interval of maximum demand for the anticipated group of consumers-a 


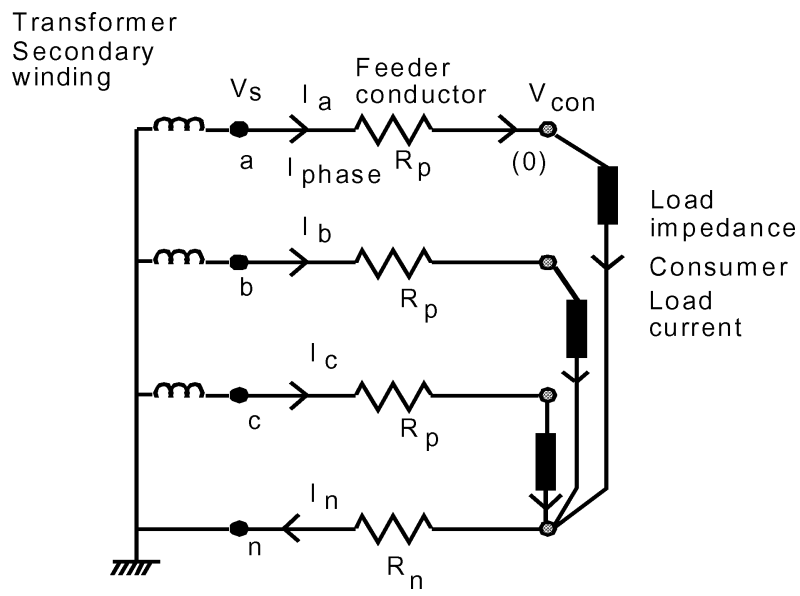

Fig. 5. 3-phase, 4-wire LV system.

common practice although it is not valid all the time for every feeder.

- The loads are represented as currents at unity power factor-at maximum demand loads residential loads tend to unity power factor.

- At any specified interval, the collective loads may be represented as a statistic whose description fits the Beta pdf.

- At this time interval, the load currents are assumed to be independently distributed - this is valid if the statistic is considered at a single time interval.

- LV feeder impedance is regarded as resistive at a specified temperature- these feeders typically have small reactances (phase spacing about $200 \mathrm{~mm}$ for bare conductors and less than $20 \mathrm{~mm}$ for aerial bundled conductors).

Theoretical development of the various Beta parameter algorithms is described in several published articles [5]-[8]. The statistical and algebraic manipulations tend to be somewhat tedious, so they will not be repeated here. We summarize the analytical procedure for deriving the method.

\section{A. Voltage Drop for a 3-Phase, 4-Wire System}

Referring to Fig. 5, suppose there are $m_{a}, m_{b}$ and $m_{c}$ consumers whose load currents are Beta distributed, and then their probable combined current may be expressed by

$$
\begin{aligned}
\mathrm{I}_{\mathrm{a}} & =\mathrm{C}\left[\mathrm{Y}_{1}+\ldots+\mathrm{Y}_{\mathrm{ma}}\right] \\
\mathrm{I}_{\mathrm{b}} & =\mathrm{C}\left[\mathrm{Y}_{1}+\ldots+\mathrm{Y}_{\mathrm{mb}}\right] \\
\mathrm{I}_{\mathrm{c}} & =\mathrm{C}\left[\mathrm{Y}_{1}+\ldots+\mathrm{Y}_{\mathrm{mc}}\right]
\end{aligned}
$$

and in phasor terms

$$
\mathbf{I}_{\mathbf{n}}=\mathbf{I}_{\mathbf{a}}+\mathbf{I}_{\mathbf{b}}+\mathbf{I}_{\mathbf{c}}
$$

where $\mathrm{C}$ is a scaling factor, such as (or larger than) the circuitbreaker size, and $\mathrm{Y}$ is a random variable, (0..Y...1), drawn from the common Beta distribution having parameters $\alpha$ and $\beta$.

Then it can be shown that the resulting voltage drop across $\mathrm{R}_{\mathrm{a}}$ is also Beta distributed, as is the consumer voltage $\mathrm{V}_{\mathrm{a}^{\prime} \mathrm{n}^{\prime}}$. The object of the analysis is to derive the parameters $\alpha^{*}$ and $\beta^{*}$ of the consumer voltage. Since there are two unknowns, two equations are required and these are determined by expressing two statistical moments of $\mathrm{V}_{\mathrm{a}^{\prime} \mathrm{n}^{\prime}}$ in terms of the network constants and the Beta parameters of the load currents, $\alpha$ and $\beta$.

The first and second moments of a Beta pdf about the origin are given by

$$
\begin{aligned}
\mathrm{E}(\mathrm{Y}) & =\mathrm{C} \frac{\alpha}{\alpha+\beta} \\
\mathrm{E}\left(\mathrm{Y}^{2}\right) & =\mathrm{C}^{2} \frac{\alpha(\alpha+1)}{(\alpha+\beta)(\alpha+\beta+1)} .
\end{aligned}
$$

The random variables at each node cannot, however, be readily summed. To calculate a random variable for the total feeder voltage drop the principle of superposition may be used. In essence, this means that if the voltage at a certain point in a circuit is the function of more than one voltage- or current source, the voltage may be written as the sum of the voltages due to each source. The voltage random variable is then a function of the sum of the random variables of each source.

In the further analysis, the value for each symbol denoted by "i" refers to the superposition value. This means that the value is calculated by removing the loads from all other nodes and calculating the effect of node "i" only. The values for all nodes are added to produce a single probability distribution for the voltage drop.

The voltage drop in the feeder section may be represented by the quadrature components: $\Re \Delta \mathrm{V}_{\mathrm{i}}$ and $\Im \Delta \mathrm{V}_{\mathrm{i}}$. With $\mathrm{m}_{\mathrm{ai}}$, $\mathrm{m}_{\mathrm{bi}}$ and $\mathrm{m}_{\mathrm{ci}}$, the number of customers connected to a-, $\mathrm{b}-$, and c-phases at node " $\mathrm{i}$ ". The minimum and maximum values for the total consumer voltage $\mathrm{V}_{\mathrm{Con}} \mathrm{t}$ can be determined as follows:

$$
\begin{aligned}
& \mathrm{V} \max =\sqrt{\left(\mathrm{V}_{\mathrm{S}}-\sum_{\mathrm{i}=1}^{\mathrm{N}} \Re \Delta \mathrm{V} \max _{\mathrm{i}}\right)^{2}+\left(\sum_{\mathrm{i}=1}^{\mathrm{N}} \Im \Delta \mathrm{V} \max _{\mathrm{i}}\right)^{2}} \\
& \mathrm{~V} \min =\mathrm{V}_{\mathrm{S}}-\sum_{\mathrm{i}=1}^{\mathrm{N}} \Delta \mathrm{V} \min _{\mathrm{i}} .
\end{aligned}
$$

$\mathrm{V}_{\mathrm{S}}$ is the sending-end voltage magnitude.

The analysis that follows requires a fair amount of tedious algebra and a moderate grasp of parametric statistics but the final result is very usable in practice.

Let $R_{s}$ be the phase conductor resistance for the section between node (i-1) and node i. $R_{t}$ is the neutral conductor resistance for the section between node (i-1) and node $i$. Then $R_{p i}$ and $\mathrm{k}_{\mathrm{i}}$ are given by

$$
\mathrm{R}_{\mathrm{pi}}=\sum_{\mathrm{s}=1}^{\mathrm{i}} \mathrm{R}_{\mathrm{s}} \quad \mathrm{k}_{\mathrm{i}}=\frac{\sum_{\mathrm{s}=1}^{\mathrm{i}} \mathrm{R}_{\mathrm{s}}}{\sum_{\mathrm{t}=1}^{\mathrm{i}} \mathrm{R}_{\mathrm{t}}}
$$

$$
\begin{aligned}
\Re \Delta \mathrm{V} \max _{\mathrm{i}} & =\frac{1}{2} \cdot \mathrm{k}_{\mathrm{i}} \cdot \mathrm{R}_{\mathrm{pi}} \cdot \mathrm{C} \cdot\left(\mathrm{m}_{\mathrm{bi}}+\mathrm{m}_{\mathrm{ci}}\right) \\
\Im \Delta \mathrm{V} \max _{\mathrm{i}} & =\frac{\sqrt{3}}{2} \mathrm{k}_{\mathrm{i}} \cdot \mathrm{R}_{\mathrm{pi}} \cdot \mathrm{C} \cdot\left(\mathrm{m}_{\mathrm{bi}}-\mathrm{m}_{\mathrm{ci}}\right) \\
\Delta \mathrm{V} \min _{\mathrm{i}} & =\left(1+\mathrm{k}_{\mathrm{i}}\right) \cdot \mathrm{R}_{\mathrm{pi}} \cdot \mathrm{C} \cdot \mathrm{m}_{\mathrm{ai}} .
\end{aligned}
$$

The first statistical moment or expected value of $\Re \Delta V_{t}$, $\mathrm{E}\left(\Re \Delta \mathrm{V}_{\mathrm{t}}\right)$ is calculated from

$$
\mathrm{E}\left(\Re \Delta \mathrm{V}_{\mathrm{t}}\right)=\sum_{\mathrm{i}=1}^{\mathrm{N}} \mathrm{E}\left(\Re \Delta \mathrm{V}_{\mathrm{i}}\right)
$$


and

$$
\mathrm{E}\left(\Re \Delta \mathrm{V}_{\mathrm{i}}\right)=\mathrm{C}_{\mathrm{mk} 1 \mathrm{i}} \cdot \mathrm{R}_{\mathrm{pi}} \cdot \mathrm{CG}
$$

where

$$
\mathrm{G}=\frac{\alpha}{\alpha+\beta}
$$

and $\mathrm{C}_{\mathrm{mkli}}$ is given by

$$
\mathrm{C}_{\mathrm{mkli}}=\left(1+\mathrm{k}_{\mathrm{i}}\right) \mathrm{m}_{\mathrm{ai}}-\mathrm{k}_{\mathrm{i}}\left(\mathrm{m}_{\mathrm{bi}}+\mathrm{m}_{\mathrm{ci}}\right) / 2 \text {. }
$$

The second moment of $\Re \Delta V_{t}$ is given by

$$
\mathrm{E}\left(\Re \Delta \mathrm{V}_{\mathrm{t}}\right)^{2}=\mathrm{R}_{\mathrm{pi}}^{2} \mathrm{C}^{2}\left[\mathrm{C}_{\mathrm{mk} 2 \mathrm{i}} \mathrm{H}+\mathrm{C}_{\mathrm{mk} 3 \mathrm{i}} \mathrm{G}^{2}\right]
$$

where the constants $\mathrm{Cmk}_{2 \mathrm{i}}$ and $\mathrm{Cmk}_{3 \mathrm{i}}$ are calculated from the network configuration and the numbers of customers connected to the phases of node "i" and

$$
\mathrm{H}=\frac{\alpha(\alpha+1)}{(\alpha+\beta)(\alpha+\beta+1)} .
$$

A similar procedure is used to derive $\mathrm{E}\left(\Im \Delta \mathrm{V}_{\mathrm{t}}\right)$

$$
\mathrm{E}\left(\Im \Delta \mathrm{V}_{\mathrm{i}}\right)=\frac{\sqrt{3}}{2} \mathrm{k}_{\mathrm{i}}\left(\mathrm{m}_{\mathrm{bi}}-\mathrm{m}_{\mathrm{ci}}\right) \cdot \mathrm{R}_{\mathrm{pi}} \mathrm{CG} .
$$

Summating the superposition elements:

$$
\mathrm{E}\left(\Im \Delta \mathrm{V}_{\mathrm{t}}\right)=\sum_{\mathrm{i}=1}^{\mathrm{N}} \mathrm{E}\left(\Im \Delta \mathrm{V}_{\mathrm{i}}\right)
$$

and

$$
\mathrm{E}\left(\Im \Delta \mathrm{V}_{\mathrm{t}}\right)^{2}=\sum_{\mathrm{i}=1}^{\mathrm{N}} \mathrm{E}\left(\Im \Delta \mathrm{V}_{\mathrm{t}}\right)^{2}+\sum_{\mathrm{m}=1}^{\mathrm{N}} \sum_{\mathrm{p}=1, \mathrm{p} \neq \mathrm{m}}^{\mathrm{N}} \mathrm{E}\left(\Im \Delta \mathrm{V}_{\mathrm{p}}\right)
$$

where

$$
\mathrm{E}\left(\Im \Delta \mathrm{V}_{\mathrm{i}}\right)^{2}=\mathrm{R}_{\mathrm{pi}}^{2} \mathrm{C}^{2}\left[\mathrm{C}_{\mathrm{mk} 4 \mathrm{i}} \cdot \mathrm{H}+\mathrm{C}_{\mathrm{mk} 5 \mathrm{i}} \mathrm{G}^{2}\right]
$$

with

$$
\begin{aligned}
& \mathrm{C}_{\mathrm{mk} 4 \mathrm{i}}=\mathrm{k}_{\mathrm{i}}^{2} \cdot 3 / 4 \cdot\left(\mathrm{m}_{\mathrm{bi}}+\mathrm{m}_{\mathrm{ci}}\right) \\
& \mathrm{C}_{\mathrm{mk} 5 \mathrm{i}}=\mathrm{k}_{\mathrm{i}}^{2} \cdot 3 / 4 \cdot\left(\mathrm{m}_{\mathrm{bi}}+\mathrm{m}_{\mathrm{ci}}\right)^{2}-\left(\mathrm{m}_{\mathrm{bi}}+\mathrm{m}_{\mathrm{ci}}\right) .
\end{aligned}
$$

Now, since the difference between $V_{S}$ and $V \operatorname{con}_{t}$ is generally small, we can use the Taylor expansion approximation

$$
\mathrm{E}\left(\mathrm{Vcon}_{\mathrm{t}}\right)=\mathrm{V}_{\mathrm{S}}-\mathrm{E}\left(\Re \Delta \mathrm{V}_{\mathrm{t}}\right)+\frac{1}{2} \mathrm{E} \frac{\left(\Im \Delta \mathrm{V}_{\mathrm{t}}\right)^{2}}{\mathrm{~V}_{\mathrm{S}}}
$$

from

$$
\begin{aligned}
\mathrm{V} \operatorname{con}_{\mathrm{t}}^{2} & =\left(\mathrm{V}_{\mathrm{S}}-\Re \Delta \mathrm{V}_{\mathrm{t}}\right)^{2}+\Im \Delta \mathrm{V}_{\mathrm{t}}^{2} \\
\mathrm{E}\left(\mathrm{V}_{\operatorname{con}}^{2}\right) & =\mathrm{E}\left(\mathrm{V}_{\mathrm{S}}^{2}-2 \mathrm{~V}_{\mathrm{S}} \Re \Delta \mathrm{V}_{\mathrm{t}}+\Re \Delta \mathrm{V}_{\mathrm{t}}^{2}+\Im \Delta \mathrm{V}_{\mathrm{t}}^{2}\right) .
\end{aligned}
$$

Further, the expected value of the normalized consumer voltage variable $\mathrm{Vcon}_{\mathrm{t}}^{*}$ is given by

$$
\mathrm{E}\left(\mathrm{V}_{\operatorname{con}}^{*}\right)=\frac{\mathrm{E}\left(\mathrm{V}_{\mathrm{t}} \mathrm{n}_{\mathrm{t}}\right)-\mathrm{V} \min }{\mathrm{V} \max -\mathrm{V} \min }=\frac{\alpha^{*}}{\alpha^{*}+\beta^{*}}
$$

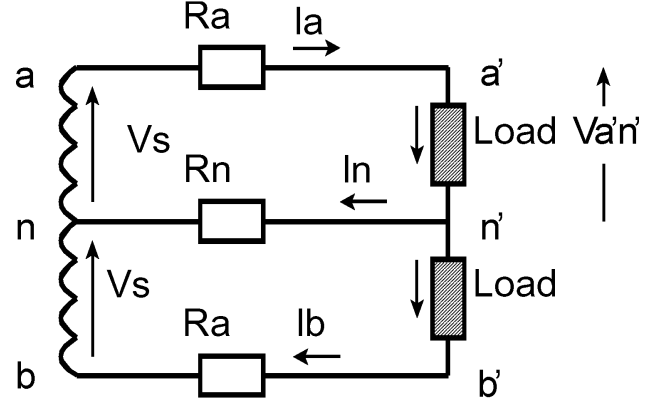

Fig. 6. Bi-phase LV system.

where $\alpha^{*}$ and $\beta^{*}$ are the parameters of the Beta pdf of the normalized consumer voltage.

Similarly

$$
\begin{aligned}
\mathrm{E}\left(\mathrm{V}_{\operatorname{con}}^{* 2}\right) & =\frac{\mathrm{E}\left(\mathrm{V}_{\mathrm{t}}{ }_{\mathrm{t}}^{2}\right)-2 \mathrm{~V} \min \cdot \mathrm{E}\left(\mathrm{V}_{\mathrm{con}}\right)+\mathrm{V} \min ^{2}}{(\mathrm{~V} \max -\mathrm{V} \min )^{2}} \\
& =\frac{\alpha^{*}\left(\alpha^{*}+1\right)}{\left(\alpha^{*}+\beta^{*}\right)\left(\alpha^{*}+\beta^{*}+1\right)} .
\end{aligned}
$$

From expressions (1) and (2) $\alpha^{*}$ and $\beta^{*}$ are easily evaluated.

A quantile value, $\hat{\mathrm{E}}\left(\mathrm{V}^{*} \mathrm{con}_{\mathrm{t}}\right)$, corresponding to a chosen level of confidence may be extracted from the voltage pdf by using the inverse Beta function available in most spreadsheets.

The actual consumer voltage for this quantile value, Vcon, is then given by

$$
\mathrm{V} \text { con }=\hat{\mathrm{E}}\left(\mathrm{V}^{*} \operatorname{con}_{\mathrm{t}}\right)(\mathrm{V} \max -\mathrm{V} \min )+\mathrm{V} \min .
$$

\section{B. Voltage Drop for a Bi-Phase System}

The analysis of the bi-phase system, shown in Fig. 6, follows the same procedure as that of the 3-phase, 4-wire network. As in the three-phase case, the principle of superposition is used. The process is simplified in that there are no phase shifts between the two a and b "phases". This eliminates the need for complex algebra. The Taylor expansion is no longer required since the first and second moments are readily derived.

The loads are again assumed to be Beta-distributed currents.

The maximum and minimum values of the customer voltage are

$$
\begin{aligned}
& \mathrm{V} \max =\mathrm{Vs}+\sum_{\mathrm{i}=1}^{\mathrm{N}} \Delta \mathrm{V} \max _{\mathrm{i}} \\
& \mathrm{V} \min =\mathrm{Vs}+\sum_{\mathrm{i}=1}^{\mathrm{N}} \Delta \mathrm{V} \min _{\mathrm{i}}
\end{aligned}
$$

where

$$
\begin{aligned}
\mathrm{V} \max _{\mathrm{i}} & =\mathrm{k}_{\mathrm{i}} \mathrm{C} \cdot \mathrm{b}_{\mathrm{i}} \mathrm{R}_{\mathrm{i}} \\
\mathrm{V} \min _{\mathrm{i}} & =-\left(1+\mathrm{k}_{\mathrm{i}}\right) \mathrm{R}_{\mathrm{i}} \mathrm{C} \cdot \mathrm{a}_{\mathrm{i}} .
\end{aligned}
$$

The total voltage drop is 


$$
\Delta \mathrm{V}_{\mathrm{t}}=\sum_{\mathrm{i}=1}^{\mathrm{n}} \Delta \mathrm{V}_{\mathrm{i}}
$$

where

$$
\Delta \mathrm{V}_{\mathrm{i}}=-\mathrm{I}_{\mathrm{ai}}\left(1+\mathrm{k}_{\mathrm{i}}\right) \mathrm{R}_{\mathrm{i}}+\mathrm{I}_{\mathrm{bi}} \mathrm{k}_{\mathrm{i}} \mathrm{R}_{\mathrm{i}} .
$$

The "phase" currents are

$$
\begin{aligned}
& \mathrm{I}_{\mathrm{ai}}=\mathrm{C}\left(\mathrm{Y}_{\mathrm{a} 1 \mathrm{i}}+\mathrm{Y}_{\mathrm{a} 21}+\ldots+\mathrm{Y}_{\mathrm{aai}}\right) \\
& \mathrm{I}_{\mathrm{bi}}=\mathrm{C}\left(\mathrm{Y}_{\mathrm{b} 1 \mathrm{i}}+\mathrm{Y}_{\mathrm{b} 21}+\ldots+\mathrm{Y}_{\mathrm{bbi}}\right) .
\end{aligned}
$$

$\mathrm{R}_{\mathrm{i}}$ and $\mathrm{k}_{\mathrm{i}}$ have the same connotation as before and the $\mathrm{Y}$ random variables lie within the range 0 to 1 with Beta parameters $\alpha$ and $\beta$.

The distribution of the consumer voltage, $\mathrm{Vcon}_{t}$ is derived from first and second statistical moments.

The expectation of $\mathrm{Vcon}_{\mathrm{t}}$ (1st moment) is given by

$$
\mathrm{E}\left(\mathrm{Vcon}_{\mathrm{t}}\right)=\mathrm{V}_{\mathrm{s}}+\sum_{\mathrm{i}=1}^{\mathrm{n}} \mathrm{E}\left(\Delta \mathrm{V}_{\mathrm{i}}\right)
$$

and

$$
\mathrm{E}\left(\Delta \mathrm{V}_{\mathrm{i}}\right)=\left(\mathrm{b}_{\mathrm{i}} \mathrm{q}_{\mathrm{i}}-\mathrm{a}_{\mathrm{i}} \mathrm{p}_{\mathrm{i}}\right) \mathrm{G}
$$

where $a_{i}$ and $b_{i}$ are the numbers of consumers connected to the $a-$ and b- phases at node 'i' and

$$
\begin{aligned}
& \mathrm{p}_{\mathrm{i}}=\mathrm{C}\left(1+\mathrm{k}_{\mathrm{i}}\right) \mathrm{R}_{\mathrm{i}} \\
& \mathrm{q}_{\mathrm{i}}=\mathrm{Ck}_{\mathrm{i}} \mathrm{R}_{\mathrm{i}} .
\end{aligned}
$$

The second moment of $\mathrm{V} \mathrm{Con}_{\mathrm{t}}$ may be expressed as

$$
\mathrm{E}\left(\mathrm{V}_{\operatorname{con}}^{2}\right)=\mathrm{E}\left[\left(\mathrm{V}_{\mathrm{s}}+\sum_{\mathrm{i}=1}^{\mathrm{n}} \Delta \mathrm{V}_{\mathrm{i}}\right)^{2}\right] .
$$

This may be expanded to

$$
\begin{aligned}
\mathrm{E}\left(\mathrm{V}_{\operatorname{con}}^{2}\right)=\mathrm{V}_{\mathrm{s}}^{2} & +2 \mathrm{~V}_{\mathrm{s}} \sum_{\mathrm{i}=1}^{\mathrm{n}} \mathrm{E}\left(\Delta \mathrm{V}_{\mathrm{i}}\right) \\
& +\sum_{\mathrm{k}=1}^{\mathrm{N}} \sum_{\substack{\mathrm{m}=1 \\
\mathrm{k} \neq \mathrm{m}}}^{\mathrm{N}} \mathrm{E}\left(\Delta \mathrm{V}_{\mathrm{k}}\right) \mathrm{E}\left(\Delta \mathrm{V}_{\mathrm{m}}\right)+\sum_{\mathrm{i}=1}^{\mathrm{N}} \mathrm{E}\left(\Delta \mathrm{V}_{\mathrm{i}}^{2}\right)
\end{aligned}
$$

where

$$
\mathrm{E}\left(\Delta \mathrm{V}_{\mathrm{i}}^{2}\right)=\mathrm{r}_{\mathrm{i}} \mathrm{H}+\mathrm{s}_{\mathrm{i}} \mathrm{G}^{2}
$$

and

$$
\begin{aligned}
\mathrm{r}_{\mathrm{i}}= & {\left[\mathrm{b}_{\mathrm{i}} \mathrm{k}_{\mathrm{i}}^{2}+\mathrm{a}_{\mathrm{i}}\left(1+\mathrm{k}_{\mathrm{i}}\right)^{2}\right] \mathrm{R}_{\mathrm{i}}^{2} \mathrm{C}^{2} } \\
\mathrm{~s}_{\mathrm{i}}= & {\left[\mathrm{b}_{\mathrm{i}}\left(\mathrm{b}_{\mathrm{i}}-1\right) \mathrm{k}_{\mathrm{i}}^{2}-2 \mathrm{k}_{\mathrm{i}}\left(1+\mathrm{k}_{\mathrm{i}}\right) \mathrm{a}_{\mathrm{i}} \mathrm{b}_{\mathrm{i}}\right.} \\
& \left.\quad+\mathrm{a}_{\mathrm{i}}\left(\mathrm{a}_{\mathrm{i}}-1\right)\left(1+\mathrm{k}_{\mathrm{i}}\right)^{2}\right] \mathrm{R}_{\mathrm{i}}^{2} \mathrm{C}^{2} .
\end{aligned}
$$

Then letting $\alpha^{*}$ and $\beta^{*}$ be the parameters of the Beta pdf of the normalized consumer voltage and using expressions (1) and (2) as before we can determine the values of $\alpha^{*}$ and $\beta^{*}$.

The calculation of the quantile value of $\mathrm{Vcon}_{t}$ follows the same procedure as before.
Single-phase systems are simply treated as a special case of either the 3-phase system or the bi-phase system.

\section{TYPICAL SPREADSHEET INPUTS AND OUTPUTS}

While the calculation steps appear to be algebraically unwieldy, the equations are all linear and may easily be incorporated into a computer program, such as a typical spreadsheet. The inputs required are:

- $\alpha, \beta$, and $\mathrm{C}$ parameters of the loads at each node;

- number of consumers on each phase at each node;

- length and conductor size for each section;

- operating temperature for the correction of the conductor resistance;

- specified level of confidence (conversely, level of risk).

Probabilistic calculations of voltage drops may thus be performed by most designers. An extensive knowledge of probability theory is not essential. Copies of the spreadsheet are available free of charge from various sources.

By using the Beta pdf to describe residential customer load currents it is also possible to develop a probabilistic method for the thermal sizing of aerial bundle conductors (ABCs) as used in electrification projects [9]. A method has also been developed for estimating the thermal loading of residential distribution transformers using the Beta pdf as a description of the load current [10]. Another development is the assessment of annual ohmic losses in residential feeders [11]. Fixed rather than probabilistically distributed loads (such as pumps for example) may be represented in the calculation procedure by using the equivalent Beta parameters as reported in [12].

\section{BenCHMARKING AND TEST RESUltS}

In South Africa, certain steps were taken to ensure that the algorithms developed in Section IV are correctly implemented into commercial design software. Firstly, the validity of the procedure was thoroughly tested against Monte Carlo simulation and compared with existing methods [13]. Secondly, a carefully selected set of benchmark networks and load types was chosen to represent a wide variety of design scenarios. The results from these tests were tabulated and made available for the testing of software using the Beta parameter method [14].

A technical committee was assigned to examine the method and incorporate it into a design guideline for application in the electricity utility environment. The resulting guide is registered as a South African Standards document [3] and is endorsed by the national utility, Eskom, and municipalities [15].

Because the new method allowed any number of customers to be connected to a particular phase at a load point, the effects of connection patterns could be examined easily, leading to interesting results that show care should be taken with assigning customers to phases in a three-phase system [16].

All the testing using Monte Carlo simulation illustrates the advantages of a direct but representative method of voltage drop calculation.

\section{General LOAD PARAMETER Forecasting}

It is to be expected that residential load research may not be a priority in many countries. The work presented in this section is intended to facilitate the use of the Beta pdf in the absence of detailed load data. 


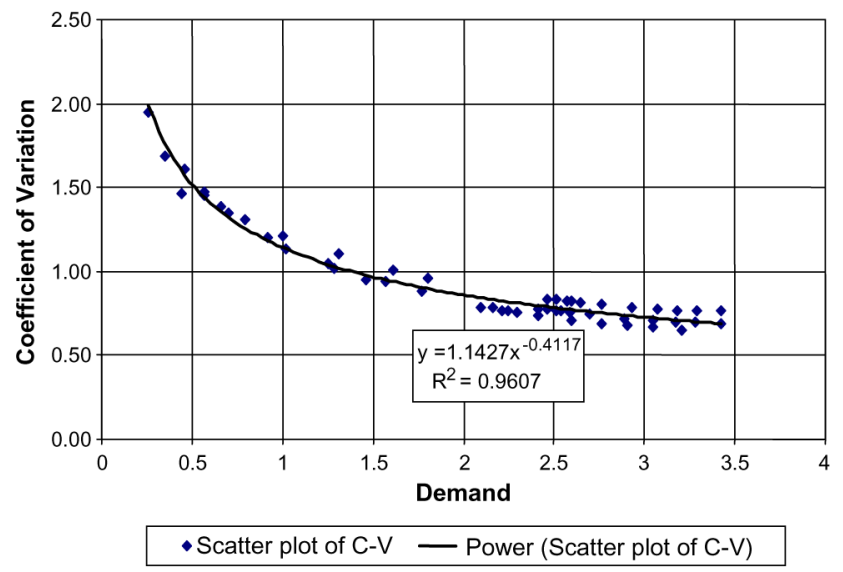

Fig. 7. Coefficient of variation versus ADMD [kVA].

The design of LV distribution systems in most countries is based on an estimated average diversified demand (ADMD). The forecasting of this load value for an identified target group of customers has been the subject of many research projects [17]. Very little though, has been written about the probabilistic distribution of residential loads. Average values alone do not provide information about dispersion or the shape of the probability distribution.

Based on the large amount of load data collected in South Africa we have examined the correlation between variance (a measure of dispersion) and ADMD for various residential customer classes. In particular, we have examined the relationship between $\mathrm{d}$ and the coefficient of variation, $\gamma$, where $\mathrm{d}$ is demand in $\mathrm{kVA}$. The coefficient of variation is defined as the ratio of standard deviation to the mean

$$
\gamma=\sigma / \mu
$$

and with Vs the supply voltage

$$
\mu=\mathrm{d} \times 10^{3} / \mathrm{Vs} .
$$

By assigning a common limiting value (the circuit breaker size in Amps) and using the expressions of mean and standard deviation for the Beta pdf, we can determine its $\alpha$ and $\beta$ parameters. The relevant expressions are

$$
\begin{aligned}
& \alpha=\frac{\mu\left(\mathrm{C} \mu-\mu^{2}-\sigma^{2}\right)}{\mathrm{C} \sigma^{2}} \\
& \beta=\frac{(\mathrm{C}-\mu)\left(\mathrm{C} \mu-\mu^{2}-\sigma^{2}\right)}{\mathrm{C} \sigma^{2}} .
\end{aligned}
$$

Our research has shown that for all the customer residential classes in South Africa the $\gamma$ versus d curve may be approximated by

$$
\gamma=1.1427 \mathrm{~d}^{-0.412}
$$

Fig. 7 shows the correlation between the curve (7) and values predicted by a forecasting tool that uses collected load data. An $\mathrm{R}^{2}$ correlation coefficient of $96.07 \%$ is indicated.

In the absence of extensive load data, this approximation should yield acceptable results in most developing countries.
Once the value of $\gamma$ has been determined the $\alpha$ - and $\beta$-parameters of the load current may be calculated and thence the calculation of the probabilistic voltage drops.

\section{CONCLUSIONS}

The South African Electricity Distribution Industry has had more than ten years experience with the algorithm and has accepted it as the prescribed design procedure. In South Africa, load models are based on extensive load data collection and interpretation. In its tabulated form the program is fast and easy to use. It is analytically accurate and does not require Monte Carlo simulation. The Beta parameter method has been proved to be more accurate than other empirical methods that ignore dispersion of load magnitudes. The validation procedure involved Monte Carlo simulation using actual measured sample load currents (sample size greater than 70). The program is practical and allows further optimization approaches, such the allocation of customers to phases.

The method has the potential for broad application in many countries where LV feeders supply several customers. Even without substantial load data collection projects, preliminary results indicate that conventional average demand data can be used as the basis for improving feeder analysis using these procedures

\section{REFERENCES}

[1] J. Carr and L. V. McCall, "Divergent evolution and resulting characteristics among the world's distribution systems," IEEE Trans. Power Del., vol. 7, no. 3, pp. 1601-1609, Jul. 1992.

[2] R. Herman and C. T. Gaunt, "Measurement and representation of maximum demand for individual andgrouped domestic consumers including constraints," in Proc. CIRED-1991 Conf., Liege, Belgium, April 1991.

[3] NRS 034-1: Electricity Distribution-Guidelines For The Provision Of Electrical Distribution Networks In Residential Areas, Part 1: Planning and Design of Distribution Systems Standards South Africa. Pretoria, South Africa.

[4] R. Herman and J. J. Kritzinger, "The statisticaldescription of grouped domestic electrical load currents," Elect. Power Syst. Res., vol. 27, pp. 43-48, 1993.

[5] R. Herman, "Voltage Regulation Analysis for the Design of Low Voltage Networks Feeding Stochastic Domestic Electrical Loads," $\mathrm{Ph} . D$. dissertation, Univ. Stellenbosch, Stellenbosch, South Africa, Nov. 1993.

[6] R. Herman, J. S. Maritz, and J. H. R Enslin, "The analysis of voltage regulation using the beta distribution model," Elect. Power Syst. Res., vol. 29, pp. 213-216, 1994.

[7] R. Herman and J. S. Maritz, "Voltage regulation algorithm for a bi-phase distribution system feeding residential customers using a Beta pdf. load model," Elect. Power Syst. Res., vol. 43, no. 2, pp. 77-80, 1997.

[8] R. Herman and S. W. Heunis, "A general probabilistic voltage drop calculation method for L.V. distributionnetworks based on a beta pdf load model," Elect. Power Syst. Res., vol. 46, no. 1, pp. 45-49, 1998.

[9] D. R. Theron and R. Herman, "Modelling of maximum temperatures in ABC's feeding domestic loads using the beta P.D.F.," Elect. Power Syst. Res., vol. 38, pp. 221-230, 1996.

[10] S. W. Heunis and R. Herman, "A thermal loading guide for residential distribution transformers based on signal-type load models," IEEE Trans. Power Syst., vol. 19, no. 3, pp. 1294-1298, Aug. 2004.

[11] S. W. Heunis and R. Herman, "Estimation of the annualresistive loss on LV residential feeders," in Proc. PMAPS-2002 Conf., Naples, Italy, Sept. 2002.

[12] R. Herman and S. W. Heunis, "Load models for mixed-class domestic and fixed, constant power loads for use in probabilistic LV feeder analysis," Elect. Power Syst. Res., vol. 66, no. 2, pp. 149-153, 2003.

[13] R. Sellick and C. T. Gaunt, "Comparing methods of calculating voltage drop in low voltage feeders," Trans SAIEE, pp. 96-111, September 1995. 
[14] R. Herman, C. T. Gaunt, and S. W. Heunis, "Benchmark tests and results for the evaluation of LV distribution voltage drop calculation procedures," Trans SAIEE, vol. 90, no. 2, pp. 54-60, 1999.

[15] I. Ferguson and C. T. Gaunt, "LV network sizing in Electrification projects-Replacing a deterministic method with a probabilistic method," presented at the Proceedings CIRED 2003 Conference, Barcelona, Spain, May 2003, Paper 68, unpublished.

[16] R. Herman, C. T. Gaunt, and S. W. Heunis, "Voltage drop effects depending on different customer feeder connections," Trans SAIEE, vol. 89, no. 1, pp. 27-32, 1998.

[17] H. L. Willis, Spatial Load Forecasting. New York: Marcel Dekker Inc., 1996.

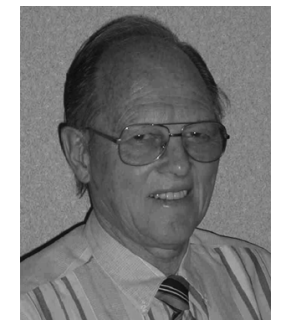

Ron Herman (SM'03) received the B.Sc. (Eng.) degree from the University of Cape Town, Rondebosch, Western Cape, South Africa, and the M.Sc. and Ph.D. degrees in electrical engineering from the University of Stellenbosch, Stellenbosch, South Africa.

After working with ESKOM, he joined the staff of the University of Stellenbosch. He developed the Herman-Beta method that is used in South African low-voltage distribution design. He is currently a part-time Research Officer at the University of Cape Town, Rondebosch, Western Cape, South Africa.

Trevor Gaunt is a Professor in the Department of Electrical Engineering, University of Cape Town, Rondebosch, Western Cape, South Africa. 